Nigerian Journal of Physiological Sciences 24 (2): 203 -206 CPhysiological Society of Nigeria, 2009

Available online/abstracted at http://www.bioline.org.br/np; www.ajol.info/journals.njps; www.cas.org

\title{
BILE SECRETION IN ALBINO RAT FOLLOWING CHRONIC HONEY INTAKE
}

\author{
E. A. ALAGWU*, R. O. NNELI ${ }^{1}$, O. O. OKWARI ${ }^{2}$ AND E. E. OSIM ${ }^{2}$ \\ * College of Medicine, Imo State University, Owerri, Nigeria, 1 College of Medicine and Health Sciences, Abia \\ State University Uturu, Nigeria. 2 College of Medical Sciences University of Calabar, Calabar, Nigeria \\ E-mail: chinayo58@yahoo.ca
}

Summary: This study was carried out to evaluate the effect of honey intake on bile secretion, bile electrolytes, bilirubin and cholesterol levels including plasma cholesterol in albino rats. 20 male albino rats (200-210g) were used in the study. The rats were assigned randomly into 2 groups (control and honey-fed groups), each group containing 10 rats. The control was fed on normal rat feed and water while the test group was fed on normal rat feed with honey added to its drinking water ( $1 \mathrm{ml}$ of honey to every initial $10 \mathrm{ml}$ of water) for 22 weeks. After 22 weeks the animals were starved for $12 \mathrm{hrs}$ before the experiment, weighed and anaesthetized with sodium thiopentone $(6 \mathrm{mg} / 100 \mathrm{mg}$ body weight) intraperitoneally. The common bile duct was cannulated and bile collected for $3 \mathrm{hrs}$. The rate of bile flow was noted, the concentrations of bile electrolytes and bilirubin, bile and plasma cholesterol levels were determined in the control and test groups. The results obtained showed a significant $(\mathrm{P}<0.05)$ decrease in the rate of bile flow in the test $(0.30 \pm 0.03 \mathrm{ml} / \mathrm{hr})$ compared with the control groups $(0.45 \pm 0.04 \mathrm{ml} / \mathrm{hr})$. There were no significant differences in the concentration of bile electrolytes and bilirubin in the two groups. However, there was a significant $(\mathrm{P}<0.05)$ increase in the bile cholesterol and decrease in plasma cholesterol levels in the test rats compared with the control. It is therefore concluded that chronic consumption of unprocessed Nigerian honey resulted in decrease bile flow, increase bile cholesterol and decrease plasma cholesterol in albino rats.

Key words: Chronic consumption, honey, bile secretion, cholesterol.

\section{Introduction}

Honey, a unique viscous liquid produced by bees from nectars of various plant products, occupied important role in the traditional medicine over 4000years ago (Postmes et al, 1993). It is widely consumed all over the world including Nigeria. The value was preached by Holy Prophet Mohammed and reported by Mohammed Marmaduke Pickthall in the Holy Qur'an, 16. Ayah 68-9 and documented by Khan (1974). Lau (1976) reported that honey was listed in the first medical handbook 2000years ago to be used in burns, cuts and abscesses. Bergman et al (1983) reported that honey was used by Russian soldiers in the First World War, to accelerate wound healing. Therapeutic effects and potentials of honey in modern medicine suffered a set back due to lack of systematic scientific studies. However, scientific support for its therapeutic potentials in many clinical and experimental trials is beginning to emerge as its effectiveness has been reported particularly where conventional treatment has failed, (Molan \& Allen 1996). Honey is used as gastric protection against acute and chronic gastric lesions in animals and treatment in gastrointestinal disorders in humans (Mobarok and Swayeh, 2003; Salem, 1981). Following wide reports on the beneficial effects of honey particularly on the wound healing and gastric protection effects, there is paucity of reports in literature on its effects on bile secretion/flow, bile electrolytes and bilirubin, bile cholesterol and plasma cholesterol levels. The aim of this study was to find out the effect of chronic honey intake on the rate of bile flow, bile electrolytes and bilirubin concentrations, bile cholesterol and plasma cholesterol levels.

\section{Materials and methods}

Twenty adult male albino rats (weighing between 200-210g) were used in the study. They were randomly assigned into control and honey-fed (test) groups comprising 10 in each group. The control group was fed on normal rat feed and water while the test group was fed on normal rat feed with honey added to the drinking water $(1 \mathrm{ml}$ of honey added to every $10 \mathrm{ml}$ of drinking water every day) for 22 weeks. After 22 weeks, the animals were starved for $12 \mathrm{hrs}$ before the experiments began. Thereafter, they were weighed and anaesthetized with sodium thiopentone $(6 \mathrm{mg} / 100 \mathrm{~g}$ body weight) intraperitoneally and quickly pinned to a dissecting board. Tracheotomy and laparatomy were performed and liver lobes were deflected anterolaterally to expose the common bile duct. The common bile duct was cannulated with a portex cannula $(0.5 \mathrm{~mm}$ diameter $)$ after a semitransection was made on the bile duct. The cannuls was held in place with thread tied over it and around the bile duct. The bile was collected for 3 hrs from each rat studied. The rate of bile flow was noted, the concentrations of bile electrolytes, bilirubin, bile and plasma cholesterol levels were determined in the control and test groups. Analysis was carried out using student t-test. $\mathrm{P}$ values less than 0.05 were considered significant. 


\section{Results}

Figures 1, 2, 3, 4, 5 and 6 represent mean values of bile sodium, chloride, potassium and bicarbonate ions, bile cholesterol and total plasma cholesterol levels, rate of bile secretion/flow and total, conjugated and unconjugated bilirubin levels in the control and test groups.

The concentrations of $\mathrm{Na}^{+}, \mathrm{K}^{+}, \mathrm{HCO}_{3}{ }^{-}$and $\mathrm{Cl}^{-}$ ions in the bile of both the control and the test groups were not significantly different $(\mathrm{P}>0.05$ figs 1 and 2). Bile cholesterol levels were significantly increased in the test group compared with the control group $(1.46 \pm 0.04 \mathrm{mmol} / 1 \quad$ vs $1.23 \pm 0.03 \mathrm{mmol} / 1,(\mathrm{P}<0.01$; figure 3$)$. Total plasma cholesterol was however, decreased significantly in the test compared with the control group $(2.30 \pm 0.5 \mathrm{mmol} / 1$ vs $27.3 \pm 0.54 \mathrm{mmol} / 1 \quad(\mathrm{P}<0.01$; figure 4). Rate of bile flow was significantly reduced in the test compared with the control $(0.30 \pm 0.03 \mathrm{ml} / \mathrm{hr}$ vs $0.45 \pm \mathrm{ml} / \mathrm{hr}(\mathrm{P}<0.05$; figure 5$)$. Total bilirubin, conjugated and unconjugated bilirubin concentrations in both test and control groups were not significantly different. $(\mathrm{P}>0.05$; figure 6).

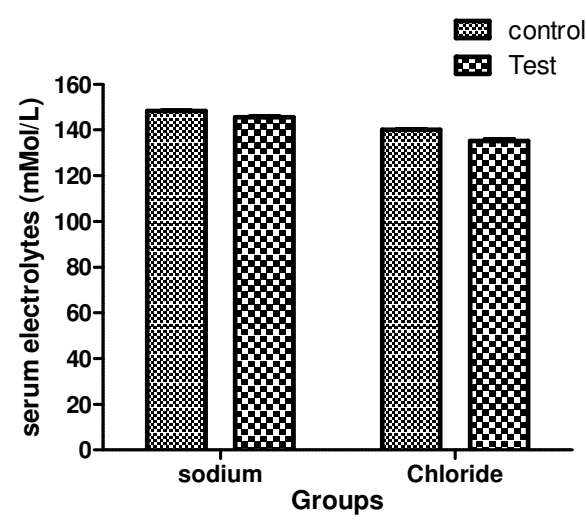

Fig. 1: Sodium and chloride ion concentration in the bile of control and test rats.

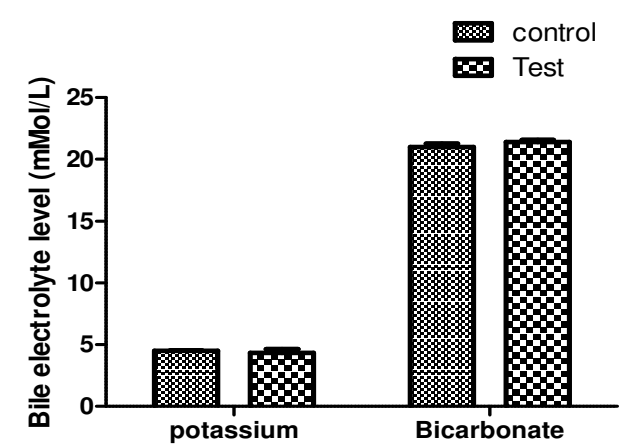

Fig. 2: Potassium and bicarbonate ions levels in bile of control and test rats.

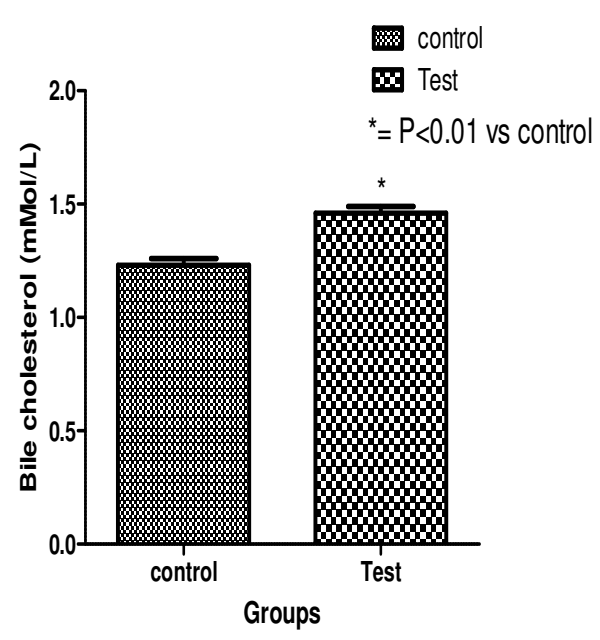

Fig. 3: Mean bile cholesterol levels in control and test rats.

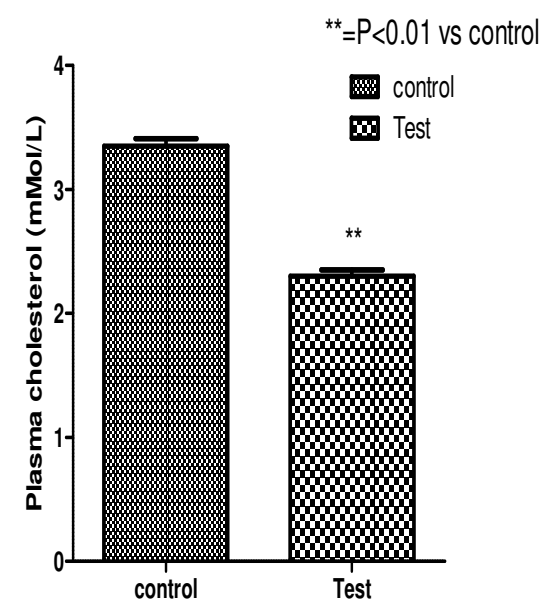

Fig. 4: Mean plasma cholesterol levels in control and test rats.

\section{Discussion}

The beneficial effects of honey on wound healings have been widely reported (Molan, 1999; Efem, 1988). There are paucity of reports in the literature on its effects on bile flow, bile electrolytes, bilirubin and bile cholesterol excretion including total plasma cholesterol levels. This study therefore, investigated the effect of honey on the above parameters using male albino rats as a model. The results obtained showed a significant decrease in the rate of bile flow in the honey-fed rats compared with the control rats. Bile electrolyte and bilirubin levels showed no significant difference in both the test and control groups. However, there was a significant increase in the bile cholesterol excretion and decrease in plasma cholesterol level in the test rats when compared with their control. 


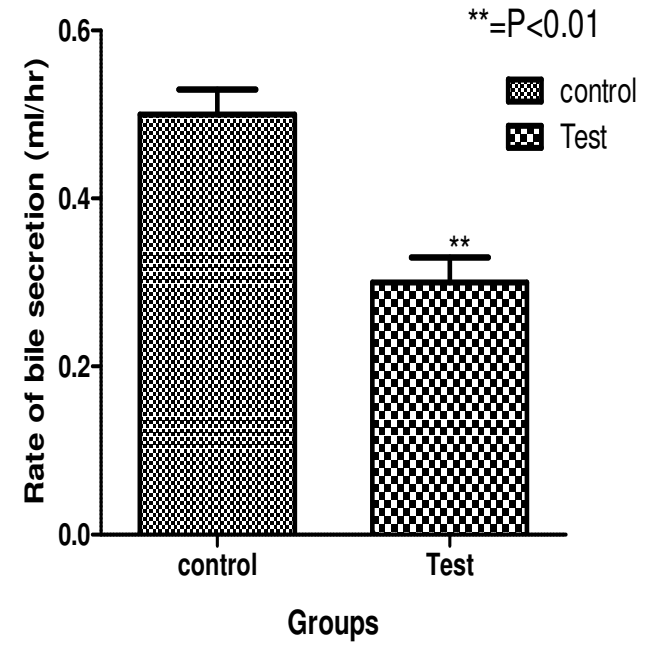

Fig. 5: Effect of honey on rate of bile secretion in rats

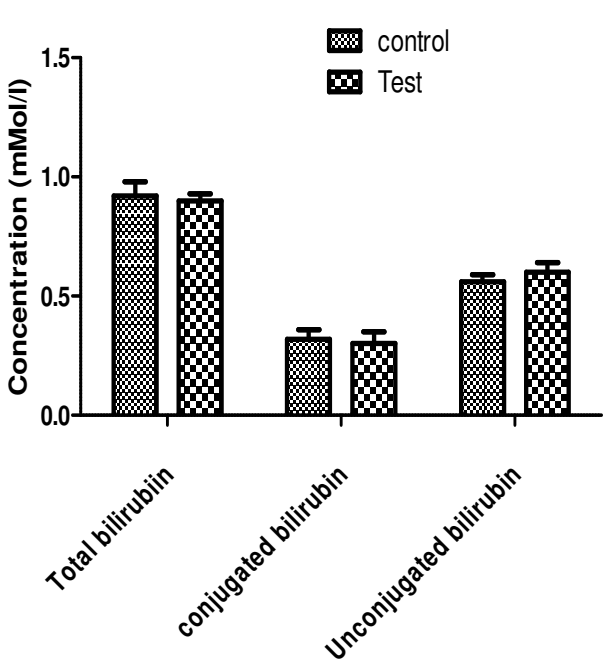

Fig. 6: Bilirubin concentrations in control and test rats

The mechanism by which honey decreased bile flow and increased bile cholesterol excretion with reduction in plasma cholesterol level in the rats is not clear. Alagwu (2008) reported that chronic honey intake caused intestinal smooth muscle relaxation and reduced intestinal transit as well as increased high density lipoproteins (HDL) in albino rats. The bile duct is composed of smooth muscle and honey intake may have caused relaxation of bile duct smooth muscles leading to a decrease rate of the bile flow. The mechanism whereby chronic consumption of honey may lower plasma cholesterol is also unknown. However, increase plasma HDL may account for the increase bile cholesterol excretion with decrease plasma cholesterol level observed in the test group. Increased plasma HDL is reported to increase cholesterol transport from the plasma and peripheral tissues to the liver (Ganong, 2003). If the results obtained in rats are applicable to man, honey intake may be beneficial in preventing hypercholesterolemia which has been implicated in the etiology and pathogenesis of atherosclerosis, myocardial infarction and stroke (Ganong, 2003). However, further studies are necessary to confirm these beneficial effects of honey in higher animals including man. In conclusion, chronic consumption of Nigerian honey reduces the rate of bile secretion and lowers plasma cholesterol in rats.

\section{References}

Alagwu, E. A (2008) Effects of Chronic Consumption of Honey in gastro-Intestinal function in Rats. Ph.D Thesis in the Department of Physiology, Abia State University, Uturu, Nigeria.

Alliam, C. C., Poor L. S, Chan, C. S. U., Richmond W. and Fu, P. C. (1974). Enzmatic determination of total serum cholesterol. Clin. Chem. 470-475.

Bahn, A. K. (1972) In: Basic Medical Statistics. New York., Grune and Straton, pp. 196-270.

Bergman A, Yanai J, Weiss J, Bell D and David MP, (1983). Acceleration of Wound Healing by Topical Application of Honey. An Animal Model. Am. J. Surg. 145: 374-376.

Deutsche Geseiischange Fur Khinische Chemic GSCC (1972). Determination of alanine phosphatase.

Efem, E. E. (1988). Chemical observations on the wound healing properties of honey. Br. J. Surg. 75. 679-681.

Frankel, E. N. (1980). Lipid peroxidation. Prog. Lipid Res. 19: 12-22.

Forrester, R. L, Watagi, L. J, Silverman, D. A. and Pierre, K. J. (1976). Ezymatic method for determination of carbonate in serum. Clin. Chem. 22, 243.

Ganong, W. F. (2003). Review of Medical Physiology. $21^{\text {st }}$ ed. Lange Medical books/Mc Graw-Hill Company Medical Publishing Division.

Jendrassik, L and Grof, P. (1938). Determination of bilirubin in plasma. Biochemistry. 297, 281.

Khan, M. M. (1974). The translation of meaning of Sahih Albukhari Al-Madina Al-Manawara Islamic University 7:395-453.

Kolthft, I. M. and Elving, J (1967). Bile chloride determination. Treatise on analytical Chemistry (Vol.1) New York W.B Sunder. 
E. A. Alagu et al

Lau, J. (1976). Bee and Honey. Melbourne Lothian Publishing Company Ltd. 1:41-9.

Mobarok Ali AM and AL Swayeh OA (2003). Honey potentiates the gastric protection effects of sucralfate against ammonia induced gastric lesions in rats. Saudi J. Gastroenterol 9:117-23.

Molan, P. C. and Allen, R. L. (1996). The antibacterial activity of honey. J. Pharm Pharmacol 48: 1206-1209.

Molan, P. C. (1999). The role of honey in the management of wounds. J. Wound Care (8) 415-418.
Postmes, T, Vande Bogaard, A. E., Hazen, M., (1993). Honey for wounds, ulcers and skin graft preservation. Lancet 31:756-757.

Reitman and Frankel (1952). Determination of Alanine Aspartate Aminotransferases. Using End point Colorimetric Diagnostic Kit (Randox Laboratory UK).

Salem, S. N. (1987). Honey regimen in gastrointestinal disorders. In: Al Awadi ARA ed. Proceedings of the First International Conference on Islamic Medicine. Kuwait Bull Islammed 1:358-62.

Received: October 20, 2009

Accepted: December 28, 2009 